\title{
Serum non-high-density lipoprotein cholesterol concentration: Profile and prevalence of high levels among adolescent Nigerian students.
}

\author{
Alphonsus N. Onyiriuka ${ }^{1}$, Nosakhare J. Iduoriyekemwen², Wilson E. Sadoh ${ }^{3}$. \\ ${ }^{1}$ Endocrinology and Metabolism Unit, Department of Child Health, University of Benin Teaching Hospital, PMB 1111, Benin City, \\ Nigeria. \\ ${ }^{2}$ Nephrology Unit, Department of Child Health, University of Benin Teaching Hospital, PMB 1111, Benin City, Nigeria. \\ ${ }^{3}$ Cardiology Unit, Department of Child Health, University of Benin Teaching Hospital, PMB 1111, Benin City, Nigeria.
}

Copyright: This is an open-access article distributed under the terms of the Creative Commons Attribution $\underline{\text { License, }}$ which permits unrestricted use, distribution, and reproduction in any medium, provided the original author and source are credited (CC BY 4.0)

\section{Abstract}

Background/Aim: Non-high-density lipoprotein cholesterol (non-HDL-C) concentration include both cholesterol-rich and triglycerides-rich atherogenic apolipoprotein B-containing lipoproteins. The present study described the distribution and estimated the prevalence of high serum non-HDL-C levels in adolescent Nigerian students.

Methods: This was a case control study, conducted in an urban secondary school. The study population consists of a total of 98 students, aged 10-16 years (49 subjects with high BMI ( $\geq 85$ th percentile) and 49 controls with normal BMI (5th to $<85$ th percentile). The first school in an alphabetically arranged list was selected. The participants were randomly selected and matched for age and sex. The serum concentrations of total cholesterol (TC), high-density lipoprotein-cholesterol (HDL-C), triglycerides (TG) and low-density lipoprotein-cholesterol (LDL-C) were determined, using automated analyzer with commercially available kits. The serum non-HDL-C concentration was determined from the difference between the TC and HDL-C concentrations.

Results: The prevalence of elevated (borderline plus abnormal) non-HDL-C concentrations in overweight/obese and normal-weight participants were 26.5\% (95\% CI=26.3-26.6) and $8.2 \%(95 \% \mathrm{CI}=5.9-14.5)$ respectively; Z-test statistic $=$ 2.666, $\mathrm{p}<0.01$. In overweight/obese participants, the prevalence rates of "borderline" and "abnormal" serum non-HDL-C levels were $24.5 \%$ and $2.0 \%$, respectively. The corresponding prevalence rates in normal-weight participants were $8.2 \%$ and zero percent, respectively. The frequency of high non-HDL-C was higher in participants whose waist-to-height ratio (WHtR) was $\geq 0.5$ than those with WHtR $<0.5$. The risk of high serum non-HDL-C level was 2.5 -fold higher in girls than boys. The mean serum non-HDL-C concentrations in overweight/obese and normal weight participants were $101.4 \pm 23.3 \mathrm{mg} / \mathrm{dl}$ and $93.6 \pm 24.8 \mathrm{mg} / \mathrm{dl}$, respectively; $\mathrm{p}>0.05$. The mean serum non-HDL-C in overweight/obese boys was $3.9 \mathrm{mg} / \mathrm{dl}$ higher than that of normal weight boys and for the girls, this difference was $10.8 \mathrm{mg} / \mathrm{dl}$.

Conclusion: The risk of developing a significantly elevated non-HDL-C level is greater in overweight/obese than normalweight adolescents and this risk is also greater in girls.

Keywords: Adolescence, non-high-density lipoprotein cholesterol, obesity, overweight, Nigeria.

Correspondence: e-mail<alpndiony@yahoo.com>. 


\section{Introduction}

The non-high-density lipoprotein cholesterol (non-HDLC) is estimated as total serum cholesterol minus the highdensity lipoprotein cholesterol concentration. It reflects the total mass of cholesterol transported in atherogenic apo B-containing lipoproteins with approximately threequarter of the cholesterol as low-density lipoprotein (LDL) and one-quarter as very-low-density lipoprotein cholesterol (VLDL) ${ }^{(1)}$. Several recent studies have confirmed the importance of non-HDL-C as a reliable, easy to calculate parameter that is strongly correlated with cardiovascular disease risk in adulthood (2-4) but limited studies have been conducted in the paediatric age group. In addition, the determination of non-HDL-C does not attract an extra cost. The serum levels of non HDL-C has been found to be related to body mass index and waist circumference (4). In one study, it was found that the difference between median values of serum non-HDL-C levels of severely obese children and those of their normal weight counterparts were approximately 20 to $30 \mathrm{mg} / \mathrm{dl}$ (5). Corey et al (6) proposed that non-HDL-C is a useful biomarker for nonalcoholic steatohepatitis. A recent study involving US children and adolescents aged 12-19 years found that elevated non-HDL-C level is associated with metabolic syndrome ${ }^{(7)}$. Recently, non-HDL-C has been established to be superior to LDL-C as a predictor of CVD risk (3,4). Sniderman et al (8), in a meta-analysis involving 233,455 subjects and 22,950 events confirmed the superiority of non-HDL-C over LDL-C in the prediction of CVD risk. Assessment of serum levels of non-HDL-C has been recommended as a target for therapy and this recommendation was based on the observation that post-prandial chylomicronaemia minimally influences the relationship between non-HDL$\mathrm{C}$ levels and coronary heart disease risk (9). In recognition of the usefulness of non-HDL-C as a biomarker of CVD risk, the American Academy of Pediatrics (AAP) in 2011, redefined dyslipidaemia by adopting the non-HDL-C level (instead of the LDL-C level), triglyceride level and HDL-C level as three major criteria for its definition (10). In an editorial, Abe (11) concluded by recommending the use of serum levels of non-HDL-C for childhood cholesterol screening.

Only few studies have examined the prevalence of elevated serum non-HDL-C levels in the paediatric age group. In this regard, the results of a study in USA involving children and adolescents showed that the prevalence of high serum non-HDL-C level varied from $11.8 \%$ to $15.0 \%$, depending on age, gender, ethnicity and weight status (12). Among Chinese children and adolescents, the reported prevalence of high serum non-HDL-C was
$4.1 \%$ (13). In literature, there are no reports from African countries (Nigeria inclusive) regarding prevalence of high serum non-HDL-C in children and adolescents, despite its usefulness as a biomarker of CVD risk in adulthood. It has been established that CVD risk factors occur in clusters and tend to track from childhood to adulthood (14). Therefore, preventive measures should begin from childhood in order to delay progression to clinical disease. The purpose of the present study was to describe the distribution and estimate the prevalence of high serum non-HDL-C levels in a selected group of overweight/obese and normal-weight adolescent Nigerian students.

\section{Participants and methods}

This was a cross-sectional study carried out in an urban secondary school in Egor Local Government Area (LGA) of Edo State, Nigeria. The study was conducted from 1st to 30th June, 2016. Ethical clearance certificate was obtained from Research and Ethics Committee of the College of Medical Sciences, University of Benin, Benin City. A written consent was obtained from the parent(s)/guardian of each of the selected students. Each study participant gave a verbal accent for the study. We emphasized to the students that their participation was entirely voluntary. In addition, permission was obtained from the administrative head of the school and the ministry of education.

\section{Study group and sampling technique}

In this study, the first private secondary school in a list of alphabetically arranged secondary schools in Egor, Local Government Area (LGA) was selected. Thereafter, the students were randomly selected. Each of the selected students was given a written note explaining the nature of the study as well as a questionnaire to be completed by their parent(s). The subjects (high BMI, $\geq 85$ th percentile) and controls (normal BMI, 5th to $<85$ th percentile) were matched for age and gender. The socio-economic status and ethnicity of the subjects and controls were similar in all respects as the school was a public school where there is no discrimination. The students attending the school were from various Nigerian social strata and ethnicity. Based on clinical assessment, any student with a positive history or obvious clinical evidence of hypothyroidism, liver disease, chronic kidney disease, Cushing syndrome, diabetes mellitus or who is on drugs such as corticosteroids or oral contraceptives were excluded from the study. 


\section{Anthropometric measurements}

Using the procedure recommended by Marfell-Jones et al (15), the height was measured to the nearest $0.1 \mathrm{~cm}$, using a Holtian portable anthropometer and the weight was measured to the nearest $0.1 \mathrm{~kg}$, using a Seca Scale Balance with the subject in light clothing and bare foot. The waist circumference was measured at the midpoint between the upper border of the iliac crest and lowest border of the last rib, at the end of normal expiration. If a duplicate measurement differed by $>0.5 \mathrm{~cm}$ or $>0.5 \mathrm{~kg}$ respectively, a third measurement was performed and the average of the two closest measurements was recorded as the final value. To eliminate inter-observer error, all the anthropometric measurements were performed by one of the authors in the presence of a chaperone. The body mass index of each of the subjects was computed, using the standard formula (15).

\section{Blood sample collection and serum lipid profile analysis}

The details of the intended procedure was explained to each of the participants before collection of blood sample. Prior to sampling, the participants maintained their usual dietary pattern within the past 3 days preceding the study. Using an aseptic technique, a venous puncture in the antecubital fossa was performed and $10 \mathrm{ml}$ of blood was collected into appropriate sample container without anticoagulant and stored at 8OC. After one hour, all samples were centrifuged at $3000 \mathrm{rpm}$ for 15 minutes and the serum aliquots were stored at $-70 \mathrm{OC}$ until assayed. The serum concentrations of total cholesterol (TC), highdensity lipoprotein-cholesterol (HDL-C) and triglycerides (TG) and low-density lipoprotein-cholesterol (LDL-C) were determined, using automated analyzer with commercially available kits and following strictly the manufacturer's instructions throughout the assay procedures.

\section{Definitions}

The non-HDL-C concentration was calculated as the TC concentration minus the HDL-C concentration (10). In the present study, we used the National Heart, Lung and Blood Institute (NHLBI) Expert Panel on Integrated Guidelines for Cardiovascular Health Risk Reduction in Children and Adolescents criteria to define high serum non-HDL-C concentration. NHLBI categorized high serum non-HDL-C into (i) borderline(120-144mg/dl) and abnormal ( $\geq 145 \mathrm{mg} / \mathrm{dl}$ ) (10). Normal weight, overweight and obesity were defined by BMI between 5 th to $<85$ th, 85th to $<95$ th and $\geq 95$ th percentiles, respectively.
Central (abdominal) obesity was defined by waist-toheight ratio $(\mathrm{WHtR}) \geq 0.5$ (16). The three phases of adolescence are early adolescence (10-13 years old); middle adolescence (14-16 years old); and late adolescence 17 years old and above) (17).

\section{Statistical analysis}

The data were collated and entered into an Excel spread sheet. Accuracy of the data entered was double checked. Subsequently, data were analysed, using Microsoft Excel and SPSS (Statistical Package for Social Sciences) version 20.0. Measures of central tendency and dispersion involving the mean and standard deviation were computed for all quantitative data. Confidence intervals, odds ratio, frequency distribution and percentages were calculated. Differences between means and prevalence were tested, using t- and Z-tests, respectively. Significant $\mathrm{p}$-value was set at $<0.05$.

\section{Results}

A total of $98(49$ overweight/obese, subjects and 49 normal weight, controls) were studied, comprising 21 boys and 28 girls in each of the two groups. The mean age of the participants was $12.9 \pm 1.2$ years, ranging between 10 and 16 years. The clinical characteristics of the participants are presented in Table 1. The mean BMI, waist-to-height and waist-to-hip ratios were separately significantly higher in overweigh/obese than normal weight group. The serum non-HDL-C levels ranged from $61.7 \mathrm{mg} / \mathrm{dl}$ to $156.6 \mathrm{mg} / \mathrm{dl}$ in overweight/obese group and $63.9 \mathrm{mg} / \mathrm{dl}$ to $135.9 \mathrm{mg} / \mathrm{dl}$ in normal-weight group. As shown in Table 2, the prevalence of elevated (borderline plus abnormal) non-HDL-C concentrations was significantly higher in overweight/obese than normalweight participants, 26.5\% (95\% CI=26.3-26.6) and 8.2\% $(95 \%$ CI $=5.9-14.5)$ respectively; Z-statistic $=2.666, \mathrm{p}<$ 0.01. Similarly, the prevalence of borderline-high nonHDL-C concentrations was significantly higher in overweight/obese than normal-weight participants, $24.5 \%$ $(95 \% \mathrm{CI}=24.4-24.6)$ and $8.2 \%(95 \% \mathrm{CI}=5.9-14.5)$ respectively; Z-statistic $=2.237, \mathrm{p}<0.05$. The only participant with a very high serum non-HDL-C level $(156.6 \mathrm{mg} / \mathrm{dl})$ was an 11 -year-old girl with waist circumference $96.5 \mathrm{~cm}$ ( $>97$ th percentile), hip circumference of $101.6 \mathrm{~cm}$ ( $>97 \mathrm{th}$ percentile), giving a waist/hip circumference ratio of 0.95 . Her blood pressure was $110 / 80 \mathrm{mmHg}$ (systolic $<90$ th percentile and diastolic 95th percentile) and BMI $26 \mathrm{~kg} / \mathrm{m} 2(>95 \mathrm{th}$ percentile). Table 3 shows prevalence of elevated non-HDL-C was significantly higher in participants whose waist-height ratio (WHtR) was $\geq 0.5$ than those whose $\mathrm{WHtR}$ was $<0.5$. 
The mean serum non-HDL-C concentrations in overweight/obese and normal weight participants were $101.4 \pm 23.3 \mathrm{mg} / \mathrm{dl}$ and $93.6 \pm 24.8 \mathrm{mg} / \mathrm{dl}$, respectively; $\mathrm{t}$ statistic $1.114, \mathrm{p}>0.05$. Table 4 shows that the mean serum non-HDL-C in overweight/obese boys was $3.9 \mathrm{mg} / \mathrm{dl}$ higher than in their normal weight counterparts. In addition, comparing overweight/obese boys and girls, the difference in mean serum non-HDL-C was $11.1 \mathrm{mg} / \mathrm{dl}$ higher in girls. The risk of high serum non-HDL-C level was 2.5-fold greater in girls than boys. In both overweight/obese and normal weight participants, the mean serum non-HDL-C concentrations was higher in females than males.

\section{Discussion}

In consonance with the reports of previous studies $(4,9,10)$, data from the present study indicate that the prevalence of elevated (borderline plus abnormal) nonhigh-density lipoprotein cholesterol was significantly higher in overweight/obese than normal-weight adolescents. This finding suggests that overweight/obesity is a risk factor for development of dyslipidaemia in adolescence. Given that dyslipidaemia is a component of metabolic syndrome, it follows that overweight/obese adolescents are at higher risk of metabolic syndrome than their normal weight counterparts. This view is supported by the results of the study by $\mathrm{Li}$ et al (7) among US youths aged 12-19 years that demonstrated increased risk of metabolic syndrome in overweight/obese subjects. The prevalence $(26.5 \%)$ of high (borderline plus abnormal) non-HDL-C levels found in the present study was comparable to $26.0 \%$ reported among Iranian students aged 11 to 18 years (18) but slightly lower than $32.5 \%$ found among Mexican adolescents (19). One-quarter of overweight/obese participants in this study had borderline-high non-HDL-C, which was in general agreement with $18.9 \%$ reported from Iran (18). Further comparison was not possible because of scarcity of published studies that have examined the subject in paediatric population. Considering the strong association between elevated serum non-high density lipoprotein level and development of metabolic syndrome, it is reasonable to advocate for initiation of health education related to consumption of healthy diet and promotion of exercise, particularly among adolescents students with borderlinehigh serum non-HDL-C value. This view is supported by the fact that cardiovascular disease risk factors are known to occur in clusters and tend to track from childhood to adulthood (14). Two percent of our subjects were in the "abnormal" category of high serum non-HDL-C level and this was lower than $4.1 \%$ and $8.1 \%$ reported among Chinese and Iranian adolescents, respectively $(13,18)$.
With regard to gender, the risk of high serum non-HDL-C level was 2.5-fold higher in girls than boys. This is consistent with the findings of previous studies $(4,13)$. Although Al-Daghari et al (20) reported a higher risk of high non-HDL-C in girls, they also noted that high serum non-HDL-C concentrations was associated with more cardiometabolic risks in boys than girls. The higher frequency of high non-HDL-C in girls may be explained by the observed higher prevalence of overweight/obesity in girls than boys, both in the present study as well as in others (4,12). This is expected, given that overweight/obesity is a known risk factor for high serum non-HDL-C levels in the paediatric population ${ }^{(5,12)}$.

Data from the present study showed that amount of body fat as measured by BMI and waist-to-height ratio (WHtR) was positively associated with serum non-HDL-C levels. The mean serum non-HDL-C was significantly higher in overweight/obese group than the normal-weight group. Similar findings have been reported in previous studies $(4,12)$. The frequency of elevated non-HDL-C was three times higher in participants with WHtR $\geq 0.5$ than in their counterparts with WHtR $<0.5$. Our finding regarding the positive association of high $\mathrm{BMI}$ and $\mathrm{WHtR} \geq 0.5$ with high serum non-HDL-C level may be explained by the influence of obesity on cholesteryl ester transfer protein (CETP) activity. General obesity (as measured by high BMI) and central obesity (as measured by WHtR $\geq$ $0.5)$ are known to induce increase in CETP activity, resulting in hypercholesterolaemia and decrease in serum high-density lipoprotein cholesterol (HDL-C) levels (21,22). Thus, accounting for the higher mean serum non-HDL-C levels observed among overweight/obese adolescents in the present study. The results of a study in Brazil suggest that waist-to-height ratio more accurately predicted dyslipidaemia than BMI (23).

The overall mean serum concentration of non-HDL-C was higher in overweight/obese than normal weight participants. A similar finding has been reported in previous studies (5,12). The mean serum non-HDL-C concentration was higher in girls than boys. This finding is consistent with the report of several studies among adolescents in USA, China, Turkey and India (12,13,24,25). The observed gender difference in serum profile of nonHDL-C may be explained by the established age- and puberty-related dynamic changes in serum lipid levels. Goff et al (26), reported that mean serum total cholesterol levels tended to be steady during prepubertal period, dropped during puberty in both sexes, with the drop being more profound in boys, and then rise again during in late adolescence. Similarly, in a study in Turkey, serum total cholesterol levels showed a more profound decline in boys 
starting from the age of 9 years until the age of 15 years and then began to rise at the age of 17 years (21). Considering that serum non-HDL-C level is derived from the difference between total cholesterol and HDL-C, a more profound decline in serum total cholesterol level in boys will result in a relatively lower serum non-HDL-C level in boys than girls. Thus, accounting for the higher serum non-HDL-C levels in girls.

In conclusion, the risk of developing a significantly elevated non-HDL-C level was higher in overweight/obese than normal-weight adolescents. It is advocated that non-HDL-C level should be estimated routinely in serum lipid panels in children and adolescents, particularly those with a high body mass index.
The strength of the study is that the subjects and controls were derived from a single well defined source population. In addition, matching increased the statistical precision of estimates, thereby allowing smaller sample size. The weakness of the study was that the study population was derived from a single school, making it possible that the sample was not representative of adolescents in the source population. Despite this limitation, it provided baseline epidemiological data (the first among Nigerian adolescents) on the subject and could serve as an initial point for future study.

\section{Conflict of interest}

We have no conflict of interest in this study.

Strengths and weaknesses of the study

Table 1. Clinical and biochemical characteristics of the subjects and controls according to gender

\begin{tabular}{lllllll}
\hline $\begin{array}{l}\text { Clinical } \\
\text { Characteristics }\end{array}$ & $\begin{array}{l}\text { Subjects } \\
\text { Male }\end{array}$ & $\begin{array}{l}\text { Controls } \\
\text { Male }\end{array}$ & $\begin{array}{l}\text { t-statistic } \\
\text { (p-value) }\end{array}$ & $\begin{array}{l}\text { Subjects } \\
\text { Female }\end{array}$ & $\begin{array}{l}\text { Controls } \\
\text { Female }\end{array}$ & $\begin{array}{l}\text { t-statistic } \\
\text { (p-value) }\end{array}$ \\
\hline Mean weight (kg) & $52.3 \pm 6.4$ & $39.1 \pm 7.8$ & $\begin{array}{l}9.158 \\
(<0.001)\end{array}$ & $40.6 \pm 5.2$ & $36.3 \pm 8.4$ & $\begin{array}{l}3.047 \\
(<0.01)\end{array}$ \\
Mean height (cm) & $149.3 \pm 6.8$ & $142.4 \pm 6.6$ & $\begin{array}{l}5.097 \\
(<0.01)\end{array}$ & $146.8 \pm 7.3$ & $140.3 \pm 5.6$ & $\begin{array}{l}4.945 \\
(<0.01)\end{array}$ \\
Mean BMI(kg/m2) & $25.32 . \pm 72$ & $16.8 \pm 2.15$ & $\begin{array}{l}9.800 \\
(<0.001)\end{array}$ & $27.7 \pm 3.3$ & $17.5 \pm 3.50$ & $\begin{array}{l}16.300 \\
(<0.001)\end{array}$ \\
Mean WC (cm) & $83.2 \pm 4.9$ & $68.8 \pm 4.1$ & $\begin{array}{l}15.777 \\
(<0.001)\end{array}$ & $88.9 \pm 5.2$ & $69.1 \pm 6.7$ & $\begin{array}{l}16.342 \\
(<0.001)\end{array}$ \\
Mean HC (cm) & $90.3 \pm 10.6$ & $70.8 \pm 8.8$ & $\begin{array}{l}9.908 \\
(<0.001)\end{array}$ & $102.3 \pm 8.7$ & $72.5 \pm 8.6$ & $\begin{array}{l}17.052 \\
(<0.001)\end{array}$ \\
Mean WC/HC ratio & $0.87 \pm 0.08$ & $0.85 \pm 0.050$ & $\begin{array}{l}3.710 \\
(<0.001)\end{array}$ & $0.9 \pm 0.05$ & $0.80 \pm 0.06$ & $\begin{array}{l}5.378 \\
(<0.001)\end{array}$ \\
Mean TC (mg/d) & $136.3 \pm 26.6$ & $124.2 \pm 23.8$ & $\begin{array}{l}1.652 \\
(>0.05)\end{array}$ & $141.0 \pm 25.8$ & $133.2 \pm 20.9$ & $\begin{array}{l}1.243 \\
(>0.05)\end{array}$ \\
Mean HDL-C(mg/d) & $37.0 \pm 5.2$ & $37.2 \pm 4.6$ & $\begin{array}{l}0.132 \\
(>0.05)\end{array}$ & $38.1 \pm 6.1$ & $37.1 \pm 5.3$ & 0.655 \\
Mean TG (mg/d) & $101.8 \pm 27.2$ & $90.3 \pm 25.6$ & $\begin{array}{l}1.414 \\
(>0.05)\end{array}$ & $102.5 \pm 23.7$ & $95.5 \pm 22.7$ & $\begin{array}{l}(>0.05) \\
(>0.129\end{array}$ \\
Mean LDL-C(mg/d) & $68.5 \pm 24.2$ & $65.7 \pm 25.8$ & $\begin{array}{l}0.363 \\
(>0.05)\end{array}$ & $76.7 \pm 20.2$ & $73.1 \pm 18.8$ & 0.690 \\
& & & & & $(>0.05)$ \\
\hline
\end{tabular}

$\mathrm{BMI}=$ Body mass index; WC = Waist circumference; $\mathrm{HC}=$ Hip circumference

TC = Total cholesterol; HDL-C = High-density lipoprotein cholesterol; TG = Triglyceride; LDL-C = Low-density lipoprotein cholesterol. 
Table 2: Prevalence of acceptable (normal), borderline and abnormal (high) non-high density lipoprotein cholesterol levels in overweight/obese and normal weight participants.

\begin{tabular}{llll}
\hline Non-high density lipoprotein cholesterol (mg/d) & $\begin{array}{l}\text { Overweight/ } \\
\text { Obese }\end{array}$ & $\begin{array}{l}\text { Normal- } \\
\text { Weight }\end{array}$ & $\begin{array}{l}\text { Z-statistic } \\
\text { (p-value) }\end{array}$ \\
\hline Acceptable (<120) & $36(73.5)$ & $45(91.8)$ & $\begin{array}{l}2.701 \\
(<0.01)\end{array}$ \\
Borderline (120-144) & $12(24.5)$ & $4(8.2)$ & $\begin{array}{l}2.237 \\
(<0.05)\end{array}$ \\
Abnormal ( $\geq \mathbf{1 4 5 )}$ & $1(2.1)$ & $0(0.0)$ & $\begin{array}{l}0.207 \\
(>0.05)\end{array}$ \\
Total & $49(100.0)$ & $49(100.0)$ & \\
\hline
\end{tabular}

Borderline plus abnormal non-HDL-C: Subjects vs controls Z-statistic 2.666 (p-value < 0.01)

Table 3: Prevalence of acceptable (normal), borderline and abnormal non-high density lipoprotein cholesterol levels in subjects and controls according to waist-height ratio.

\begin{tabular}{llll}
\hline Non-high density lipoprotein cholesterol (mg/dl) & $\begin{array}{l}\text { WHtR } \\
\mathbf{2 0 . 5}\end{array}$ & $\begin{array}{l}\text { WHtR } \\
<\mathbf{0 . 5}\end{array}$ & $\begin{array}{l}\text { Z-statistic } \\
\text { (p-value) }\end{array}$ \\
\hline Acceptable (<120) & $36(73.5)$ & $45(91.8)$ & $\begin{array}{l}2.701 \\
(<0.01)\end{array}$ \\
Borderline (120-144) & $12(24.5)$ & $4(8.2)$ & $\begin{array}{l}2.237 \\
(<0.05)\end{array}$ \\
Abnormal ( $\mathbf{1 4 5 )}$ & & & 0.207 \\
& $1(2.1)$ & $0(0.0)$ & $\begin{array}{l}(>0.05) \\
\text { Total }\end{array}$ \\
\hline
\end{tabular}

WHtR $=$ Waist-to-height ratio

Table 4: Mean serum non-high-density lipoprotein concentrations and prevalence of elevated levels in overweight/obese and normal-weight participants, according to gender.

\begin{tabular}{|c|c|c|c|}
\hline Parameter & $\begin{array}{l}\text { Overweight/ } \\
\text { Obese }\end{array}$ & Normal weight & $\begin{array}{l}\text { Statistical } \\
\text { analysis }\end{array}$ \\
\hline $\begin{array}{l}\text { Mean } \pm \text { SD serum non-HDL-C } \\
\text { concentration }\end{array}$ & & & t-test \\
\hline Males(21)a & $95.0 \pm 25.2$ & $91.1 \pm 24.7$ & \\
\hline Females(28)b & $106.1 \pm 21.9$ & $95.3 \pm 22.5$ & $\begin{array}{l}a \quad \text { vs b: } \\
1.613 ; \\
p>0.05\end{array}$ \\
\hline Both sexes(49) & $101.4 \pm 23.3$ & $93.6 \pm 24.8$ & \\
\hline $\begin{array}{l}\text { Prevalence }(\%) \text { of high non-HDL-C } \\
\text { concentration }\end{array}$ & & & Z-test \\
\hline Males(21)c & $3(14.3)$ & $1(4.8)$ & \\
\hline Females(28)d & $10(37.5)$ & $3(10.7)$ & $\begin{array}{l}\text { c vs d: } \\
1.946 ; \\
p>0.05\end{array}$ \\
\hline Both sexes(49) & $13(26.5)$ & $4(8.2)$ & \\
\hline
\end{tabular}


1. Sniderman AD, Hogue JC, Bergeron J, Gagué C, Couture P. Non HDL cholesterol and apoB in dyslipidaemia. Clin Sci (Lond) 2008;114:149-155.

2. Srinivasan SR, Frotini MG, Xu J, Berenson GS. Utility of childhood non-high density lipoprotein cholesterol levels in predicting adult dyslipidaemia and other cardiovascular risks: The Bogalusa Heart Study. Pediatrics 2006;118:201-206.

3. Zhu WF, Liang L, Wang CL, Fu JF. Triglyceride and non-high-density lipoprotein cholesterol as predictors of cardiovascular disease risk factor in Chinese Han children. Indian Pediatr 2013;50:394-398.

4. Srinivasan SR, Myers L, Berenson GS. Distribution and correlates of non-high-density lipoprotein cholesterol in children: The Bogalusa Study. Pediatrics 2002;110(3):e29.

5. Sugiura R, Okada T, Yamauchi K, Murata M. The influence of underweight or obesity to lipid profiles in Japanese children. J Child Health 2015;74:656-661.

6. Corey KE, Lai M, Gelrud LG, Misdraji J, Barlow LL, Zheng H, et al. Non-high-density lipoprotein cholesterol as a biomarker of nonalcoholic steatohepatitis. Clin Gastroenterol Hepatol 2012;10:651-656.

7. Li C, Ford ES, McBride PE, Kwiterozich PO, McCrindle BW, Gidding SS. Non-high-density lipoprotein cholesterol concentration is associated with metabolic syndrome among US youths aged 12-19 years. J Pediatr 2011;158:201-207.

8. Sniderman AD, Williams K, Contois JH, Monroe HM, McQueen MJ, de Graaf J, Furberg CD. A meta-analysis of low density lipoprotein cholesterol, non high density lipoprotein cholesterol and apolipoprotein B as markers of cardiovascular risk. Circ Cardiovasc Qual Outcomes 2011;4:337-345.

9. Miller M, Cannon CP, Murphy SA, Qin J, Ray KK, Braunwald E. Impact of triglyceride levels beyond low-density lipoprotein cholesterol after acute coronary syndrome in the PROVE IT-TIMI 22 Trial. J Am Coll Cardiol 2008;51:724-730.

10. Expert Panel on Integrated Guidelines for Cardiovascular Health and Risk Reduction in Children and Adolescents; summary report. Expert panel on integrated guidelines for cardiovascular health and risk reduction in children and adolescents; National Heart, Lung and Blood Institute. Pediatrics 2011;128(Suppl 5):S213-S256.

11. Abe Y. Difference in serum non-high-density lipoprotein cholesterol levels in terms of sex, age, and physique in children and adolescents. J Atheroscler Thromb 2016;23:1311-1312 [Editorial].

12. Dai S, Yang Q, Yuan K, Loutalot F, Fang J, Daniels SR, Hong Y. Non-high-density lipoprotein cholesterol: Distribution and prevalence of high serum levels in children and adolescents: United States National Health and Nutrition Examination Surveys, 2005-2010. J Pediatr 2014;164(2):247-253.

13. Fang TL, Liang L, Fu JF, Gong CX, Xiong GC, Liu GL, Luo FH, Cheng SK. Levels of non-high density lipoprotein cholesterol and its related factors in Chinese Han students. HKJ Paediatr (new series) 2013;18:210-216.

14. Bao W, Srinivasan SR, Wattigney WA, Berenson GS. Persistence of multiple cardiovascular risk clustering related to syndrome X from childhood to young adulthood. Arch Intern Med 1994;154:1842-1847.

15. Marfell-Jones M, Olds T, Stewart A, Carter L. International Standards for Anthropometric Assessment, 2nd edition. The International Society for the Advancement of Kinanthropometry, Australia, 2006.

16. McCarthy HD, Ashwell M. A study of central fatness using waist-to-height ratio in UK children and adolescents over two decades supports the simple message - 'keep your waist circumference to less than half your height'. Int J Obes (Lond) 2006;30:988-992.

17. Sass AE, Kaplan DW. Adolescence. In: Hay WW Jr, Levin MJ, Deterding RR, Abzug MJ (eds). Current Diagnosis and Treatment: Pediatrics 22nd edition, McGraw Hill Education Publishers, New York, 2014:117-157.

18. Taheri F, Chahkandi T, Kazemi T, Bijari B, Zardast M, Namakin K. Lipid profiles and prevalence of dyslipidemia in Eastern Iranian adolescents, Birjand, 2012. Iran J Med Sci 2015;40(4):341-348.

19. Bililoni MD, Salas R, De la Garza YE, Villurreal JZ, Sureda A, Tur JA. Serum lipid profile, prevalence of dyslipidaemia and associated risk factors among northern Mexican adolescents. J Pediatr Gasteroenterol Nutr 2016;63:544-549.

20. Al-Daghari NM, Aljohani NJ, Al-Attas OS, Al-Saleh Y, Wani K, Alnaami AM, Alfawaz H, Al-Ajlan ASM, Kuman S, Chrousos GP, Alokail MS. Non-high-density lipoprotein cholesterol and other lipid indices vs elevated glucose risk in Arab adolescents. J Clin Lipidol 2015;9(1):35-41.

21. Asayama K, Hayachibe H, Dobashi K, Uchida N, Nakane T, Kodera K, Shirahata A. Increased serum cholestyrl ester transfer protein in obese children. Obesity Res 2002;10(6):439-446.

22. Mietinen TA, Gylling H. Cholesterol absorption efficacy and sterol metabolism in obesity. Atherosclerosis 2000;153:241248.

23. de Quadros TMB, Gordia AP, da Silva LR. Predictive capacity of anthropometric indicators for dyslipidemia screening in childhood and adolescents. J Pediatr (Rio J) 2015;91(5):455-463.

24. Uçar B, Killiç Z, Dinleyci EC, Çolak O, Günes E. Serum lipid profiles including non-high density lipoprotein cholesterol levels in Turkish school children. Anadolu Kardiyol Derg 2007;7:415-420.

25. Nijaguna N, Vani HN, Niranjan HS, Suresh TN, Sanjeeva GN. Study of lipid profile and prevalence of dyslipidemia in adolescent school children from Karnataka. Int J Pharm Biol Sci 2015;5(1):79-85. 
26. Goff DC Jr, Donker GA, Rgan JA Jr, Adikins AT, Killinger RP, Candill JW Jr, et al. Cholesterol screening in pediatric practice. Pediatrics 1991;88:250-258. 